\title{
Participação social e promoção da saúde: estudo de caso na região de Paranapiacaba e Parque Andreense
}

\author{
Social participation and health promotion: a case study \\ in the region of Paranapiacaba and Parque Andreense
}

Elaine Cristina da Silva ${ }^{1}$

M aria Cecília Focesi Pelicioni ${ }^{2}$

\footnotetext{
${ }^{1}$ Departamento deM eio Ambiente, Prefeitura M unicipal de Santo André, São Paulo, Brasil. Av. Dr. Arnaldo 715/Térreo, Cerqueira César. 01246-904 São Paulo SP e crissilva@yahoo.com.br 2 Departamento dePrática deSaúdePública, Faculdade deSaúdePública, UniversidadedeSão Paulo.
}

Abstract Community participation is considered a key condition for communities to assume control of their health within the scope of health promotion. This study sought to identify and analyze the perceptions of residents of the watershed areas of Santo André/São Paulo with respect to the actions of health education and environmental education developed by the public authorities of the city, and how the local community participatesin these processes. Data collection was conducted via structured and semi-structured interviews with civil servants and local residents. The methodology of content analysis proposed by Bardin wasused for data interpretation. Themain results showed that the health measures developed in the region studied arestill predominantly viewed from thestandpoint of prevention and not as an educational process able to support and achieve some of the goals of health promotion, such as the development of personal skillsand support for community action. Data analysis showed the importance of intersectorial activity and conducting emancipatory educational measures as a key factor for participative procedures and the empowerment of the population.

Key words Health promotion, Education, Social participation
Resumo No âmbito da promoção da saúdea participação é considerada como uma das condições fundamentais para que as comunidades assumam o controlesobresua saúde. Esteestudo buscou identificar e analisar as percepções dos moradores das áreas de mananciaisdeSanto André/São Paulo em relação às ações de educação em saúde e de educação ambiental desenvolvidas pelo poder público deste município e às formas de participação da comunidade local nestes processos. A coleta de dados deu-se por meio de entrevistas estruturadas e semiestruturadas com funcionários públicos e moradores locais. Para interpretação dos dados obtidos foi utilizada a metodologia de análise de conteúdo proposta por Bardin. Os principais re sultados mostraram que as ações de saúde desenvolvidas na região de estudo ainda são vistas predominantemente sob o prisma da prevenção e não como um processo educativo capaz de subsidiar e alcançar alguns dos objetivos da promoção da saúde, como o desenvolvimento de habilidades pessoais e o reforço à ação comunitária. Os dados obtidos evidenciaram a importância da intersetorialidadee da realização deações educativas emancipadoras como fator primordial dos processos participativos e do "empowerment" da população. Palavras-chave Promoção da saúde, Educação, Participação social 
Introdução

"Gosto de ser homem... porque sei... Que o meu "destino" não é um dado, mas algo que precisa ser feito e de cuja responsabilidadenão posso me eximir. Gosto de ser gente porque a História em quemefaço com os outros ede cuja feitura tomo parte éum tempo de possibilidades e não de de terminismo"1.

0 fragmento acima trata de uma condição implicitamente inerente ao ser humano e que é construída socialmente, quando Freire diz que nossa História é um tempo de possibilidades e que nos fazemos com os outros tomando parte deste processo, 0 autor está se referindo ao ato da participação que apesar de ser abordado exaustivamentenos dias de hoje, vem sendo praticado na maioria das vezes de forma contrária ao seu verdadeiro significado, ou seja, assume um caráter apenas de consulta desprovida de uma visão emancipatória capaz de romper com o fatalismo diante das mudanças sociais.

A História não éestática, écíclica, por isso, a participação em que o homem interage com 0 meio na condição de sujeito é aquela que cria possibilidades para a transformação social, portanto, deve ser ativa e deliberativa, ou seja, o sujeito não será simplesmente um espectador, ele deverá interpretar, analisar, dialogar e agir sobre a realidade em que está inserido estimulando também a cooperação coletiva.

A palavra "participação" tem aparecido nos mais variados discursos, mas afinal, se existem diferentes formas de participação, de qual estamos falando? Considerando o escopo deste artigo, a participação será enfocada sob o âmbito da promoção da saúde.

A promoção da saúde "processo de capacitação da comunidade para atuar na melhoria de sua qualidade de vida e saúde", já prevêa necessidade de haver maior participação neste procesSO $^{2}$. Esta definição éoriunda da Carta de Ottawa, documento resultante da Primeira Conferência Internacional sobre Promoção da Saúde. Evento que aconteceu no Canadá em 1986, oito anos após a Conferência Internacional sobre Cuidados Primários de Saúde, em Alma Ata (Geórgia) onde a meta estabelecida foi a de "Saúde Para Todos no Ano 2000. Muitas das recomendações constantes na Carta de Ottawa basearam-se na Declaração de Alma Ata, principalmente no que diz respeito à participação. Um exemplo desta constatação é o princípio da Carta que se refere ao reforço a ação comunitária, que não resume se apenas a uma participação "física", mas sim a uma participação ativa e deliberativa, há um estímulo ao incremento do poder das comunidades, manifestado pela "posse e o controle dos seus próprios esforços e destino". Já faz 30 anos desde Alma Ata, a participação assim como os demais de seus objetivos ainda não foram alcançados de forma plena e representam ainda um grande desafio.

As conferências posteriores à Ottawa diferem por algumas particularidades, mas todas tiveram como resultado documentos que mencionam a participação como fator essencial à promoção da saúde.

No que diz respeito à participação, na D eclaração deAdelaide (1988) foram estabelecidas re lações entre as ações comunitárias e as políticas públicas saudáveis. Neste tipo de política, a intersetorialidade, assim como o envolvimento da população são primordiais e estão relacionadas com o compromisso político dos governos.

Ainda considerando os eventos sobre Promoção da Saúde, em 1991 foi realizada a Terceira Conferência Internacional que teve como foco principal os ambientes favoráveis à saúde. Uma das estratégias fundamentais configurou-se como a capacitação da comunidade edos indivíduos para que tivessem controle sobre sua saúde e ambiente por meio de educação e maior participação nos processos de tomada de decisão.

Importantes conferências aconteceram também nos anos de 2000, 2005 e 2009, no M éxico, em Bangkok e Nairóbi, respectivamente. Estes eventos trouxeram contribuições relevantes, pois ressaltaram que o desenvolvimento social é responsabilidade central dos governos e que deve ser compartilhada entre todos os setores da sociedade, enfatizando a importância da equidade em termos de saúde e estabelecendo como ações prioritárias a inclusão da promoção da saúde em políticas e programas do nível local ao internacional. Outros aspectos estiveram relacionados aos determinantes de saúde no mundo globalizado e aos benefícios que a ampliação dos meios de comunicação de massa poderia repre sentar para troca de experiências na área da promoção da saúde, ressaltando que o progresso para um mundo mais saudável requer forte ação política, ampla participação e advocacia sustentável. Além do combateàs iniquidades em saúde, atuação em redes, capacitação e criação de oportunidades e espaços para empoderamento das comunidades como condições fundamentais a este processo. A relevância da intersetorialidadee promoção da justiça social também foram ressaltados, assim como a construção de capacida- 
des dos indivíduos e das instituições para promoção da saúde, fortal ecimento dos sistemas de saúde apoiado na equidade, o fortalecimento de alianças reconhecendo a importância do envolvimento da sociedade civil neste processo e a alfabetização em saúde baseadas nas necessidades e prioridades comunitárias.

Diante do exposto, percebe-se queos processos de participação são essenciais para a manutenção da saúde de cada indivíduo e da coletividade, mas alcançar "saúde para todos no ano 2000" tem sido um grande desafio que, além do incentivo à participação, envolve fatores culturais, socioeconômicos e políticos. É inegável que todos os documentos resultantes dos encontros e conferências sobre promoção da saúde têm grande importância para o seu avanço, mas é um discurso mais filosófico do que prático.

Para Valla e Stotz ${ }^{3}$, vivemos numa intrigante contradição, pois ao mesmo tempo em que os discursos sobre participação foram se intensificando seus níveis são cada vez mais baixos. Este fato também é ratificado por Sawaia ${ }^{4}$, ao afirmar que a participação é um "conceito "fashion" enaltecido como condição detudo queé positivo na sociedade". Devemos refletir sobre o tipo de "participação" que vem sendo incentivado, bem como seu significado e objetivos. Há uma série de definições possíveis para o termo, porém neste artigo será considerada a participação social.

Antes de conceituá-la é de suma importância resgatar suas origens. Autores como $\mathrm{Demo}^{5}$, Adorno $^{6}$, Bógus 7 , Jacobi ${ }^{8}$, Westphal ${ }^{9,10}$ e Gohn ${ }^{11}$ enfatizam a importância que os movimentos sociais tiveram para os processos de participação. À medida que foram ganhando visibilidade, a participação foi se fortalecendo.

A participação não se limita a política partidária ou ao movimento sindical. Para Valla ${ }^{12}$, houve uma banalização do termo, pois muitas vezes participação é confundida com a realização de mutirões ou o acesso da população às modernizações.

É importante lembrar que o termo participação e sua prática podem assumir várias formas. Portanto, estar presente em determinadas ações em uma comunidade, por exemplo, não caracteriza efetivamentea participação social preconizada no âmbito da promoção da saúde. $\mathrm{Na}$ prática ela deve envolver toda a coletividade, levando a uma dimensão política, pois só assim poderá interferir nos vários setores da sociedade e modificar a sua relação com o Estado.

Em relação à criação de espaços de participação uma das dificuldades ao desenvolvimento da participação são as barreiras existentes na real criação desses espaços ${ }^{13}$. Geralmente o termo "participação" é utilizado na área de saúde para designar ações pontuais nas quais se convida a população à prevenção eao controle de doenças. É pertinente ressaltar que prevenir e controlar as doenças são ações importantes que devem estar atreladas a processos de promoção da saúde, mas não devem ser confundidas nos âmbitos conceitual e prático.

Trabalhar a prevenção à luz dos princípios da promoção da saúde pressupõe que a população participe de todo o processo, da problematização atéa proposição de soluções e quenão seja mobilizada apenas segundo os problemas identificados pela instituição ou objetivos de um programa específico. A participação que vai ao encontro dos pressupostos da promoção da Saúde deve estimular o empoderamento da população.

Segundo Cerqueira e Coe ${ }^{14}$, "empoderamento é o processo em que grupos de indivíduos e comunidades utilizam seu "poder" para coletivamente analisar problemas, propor soluções, administrar recursos e agir efetivamente para transformar suas vidas e seus ambientes". Por meio do empoderamento a comunidade desenvolve habilidades para ter controle sobre a sua própria saúd dee exercer a sua partici pação de forma autônoma.

Voltando às discussões sobre a participação e os impasses entre os seus objetivos e a sua prática, no final da década de 1980, a partir de análises de experiências em participação em saúde, percebeu-sea necessidade da reformulação deste conceito. Surgiu assim, o conceito de participação social "como um modelo de cogestão social que incorpora a negociação como instrumento de interação entre os atores sociais e reconhecea necessidade de construir o protagonismo dos atores através da capacitação para a tomada de decisões"13.

N ota-sequeo conceito de participação social é bem amplo engloba diversos atores sociais e é mais adequado ao alcance dos objetivos da promoção da saúde, pois evita que a comunidade seja culpabilizada por possíveis fracassos em relação às ações de promoção à saúde. Segundo Valla ${ }^{12}$, a culpabilização das vítimas ocorre, muitas vezes, pela desqualificação do saber popular, quando o saber técnico se sobrepõeao saber acumulado pela comunidade desconsiderando- 0 .

Para Gadotti e Gutiérrez ${ }^{15}$, no entanto, "a participação, quando existe de fato, é necessariamente educativa". Considerando esta afirmação, a desqualificação do saber popular é inconcebí- 
vel, épreciso levar em conta o conhecimento que a comunidade já possui e que é proveniente de suas experiências.

0 respeito ao saber popular ea dialogicidade irão favorecer 0 envolvimento das comunidades nos processos de promoção à saúde. Desta forma, a participação social é fundamental ao empoderamento da população para o controle de sua própria vida e saúde desde que tenha esse cunho educativo e político.

Considerando este aspecto, faz-se necessária a criação de uma cultura participativa ${ }^{16}$. Neste sentido, a participação social se torna um meio e um fim, à medida que favorecerá o estímulo a formas de relação baseadas na negociação e reciprocidade entre os diversos atores sociais.

Sabemos que a participação social é essencial ao processo de promoção à saúde, mas como garantir que esta participação seja autônoma, consciente equeseja inclusiva, objeto denegociação e de ação conjunta? Para que a população participe é necessário entender "por que participar" e "como participar". Sob estes aspectos os processos educativos são fundamentais, pois por meio destes são criadas condições para que os indivíduos reconheçam-se como sujeitos de sua própria educação e de sua própria história. Para Pelicioni ${ }^{17}$, "o amadurecimento da capacidadecrítica e reflexiva éresultado da participação consciente na sociedade", ou seja, os dois processosacontecem concomitantementee se complementam.

N este sentido, considerou-seimportantetrabalhar estes aspectos em uma pesquisa qualitativa que foi realizada em duas áreas (Parque Re presa Billings III e Chácara Carreiras) da região de Paranapiacaba e Parque Andreense, Município de Santo André, porção sudeste da região metropolitana de São Paulo.

O município possui $55 \%$ do seu território em área de proteção aos mananciais. A conservação desta área tem sido afetada pelos impactos de correntes das ações antrópicas locais que têm acarretado sérios problemas de saneamento e degradação ambiental e consequentemente, produzido problemas de saúde pública.

Segundo dados do $\mathrm{IBGE}^{18}$, a região de estudo possui uma população de 6.399 pessoas. O Parque Represa Billings III possui 1095 habitantes e a Chácara Carreiras possui 462 habitantes.

O poder público municipal vem desenvolvendo nestas áreas, uma série de ações fiscalizatórias, de educação em saúdee ambiental para garantir a conservação ambiental e a promoção da saúde. Porém, fortal ecer a participação comunitária nesses processos tem sido um grande desafio.
Assim, os objetivos desta pesquisa foram identificar e analisar os meios pelos quais o poder público do município de Santo André tem incentivado a participação social como estratégia para a promoção da saúde; identificar possíveis obstáculos na relação entre as ações de educação em saúde e educação ambiental promovidas na região de estudo e a participação da sociedade civil e propor estratégias que contribuam para a implementação de ações educativas de melhoria da qualidade de vida com a participação da comunidade.

\section{Metodologia}

Adotou-se na pesquisa uma abordagem metodológica quali-quantitativa. Foram realizadas pesquisas documentais incluindo: levantamento de dados estatísticos e históricos sobre a região de estudo e entrevistas estruturadas e semiestruturadas tanto com moradores da região quanto com alguns funcionários do poder público para levantamento de informações, representações e opiniões sobre as ações desenvolvidas e sua relação com a participação social.

$\mathrm{Na}$ comunidade, as primeiras abordagens foram feitas com lideranças locais indicadas pelo Departamento de M eio Ambiente. N este caso, a técnica de amostragem utilizada foi snowball sampling. As entrevistas abordavam questões sobre as representações sociais dos participantes sobre saúde, meio ambiente, área demanancial eparticipação social, bem como aspectos das ações de educação em saúdeeambiental desenvolvidas na área de estudo. As mesmas foram iniciadas após prévia aprovação do Comitê de Ética em Pesquisa da FaculdadedeSaúdePública econsentimento livre eesclarecido dos entrevistados. Por se tratar de um estudo com envolvimento de seres humanos, as resoluções 196/1996 19 e 304/200020 do Conselho Nacional de Saúde em seus aspectos éticos, foram seguidas.

Para maior segurança quanto aos dados coletados todas as entrevistas foram gravadas e transcritas de forma fidedigna. Para interpretação dos dados obtidos foi utilizada a metodologia de análise de conteúdo proposta por Bar$\operatorname{din}^{21}$. Segundo a autora, esta metodologia se constitui como um conjunto detécnicas que tem como principal objetivo o "conhecimento de variáveis de ordem psicológica, sociológica, histórica... por meio de um mecanismo de dedução com base em indicadores reconstruídos a partir de amostra de mensagens particulares", é feita 
uma análise para desvendar os reais significados, aquilo que está implícito nas palavras sobre as quais se faz o estudo.

Nesta pesquisa, algumas falas foram categorizadas e outras foram destacadas para justificar e compreender os aspectos de maior relevância referentes ao objeto de estudo. A categorização foi feita em função das respostas dadas pelos entrevistados, exatamente conforme expresso por elas. As entrevistas nas áreas de estudo foram finalizadas à medida que se percebeu um padrão repetido nas respostas dadas, ou seja, foram finalizadas por saturação.

Participaram desta pesquisa 20 funcionários da Prefeitura de Santo André que atuam na re gião de estudo. $\mathrm{N}$ a comunidade, 141 moradores adultos foram entrevistados, 100 do Parque Represa Billings III e 41 da Chácara Carreiras.

\section{Resultadosediscussão}

\section{As percepções dos funcionários} que atuam na região

Do Departamento de M eio Ambiente foram entrevistados dez funcionários. Q uando questionados sobre o que achavam da participação da comunidadenas atividades realizadas, todos responderam que a participação é insatisfatória e que deveria melhorar. Quanto aos motivos pelos quais a comunidade não participava, as respostas indicaram três motivos principais: interesse específico da população sobre determinado assunto, falta de vínculo com a região e existência de um bloqueio em relação às atividades promovidas pelo Departamento.

$\mathrm{Na}$ opinião dos entrevistados havia também uma dificuldade da população em aliar a conservação ambiental ao atendimento de suas necessidades. Outro aspecto importante levantado é em relação ao papel que a comunidade exerce sobre a área de manancial, ou seja, não há o re conhecimento por parte da população que seus atos influenciam na qualidade dos mananciais.

DaGerência deSaúdeforam entrevistados dez agentes comunitárias de saúde, das quais apenas uma classificou a participação da comunidade como satisfatória. Em geral, as agentes dizem que há falta de interesse por parte da população e que o número de pessoas que participam das atividades poderia ser maior. As agentes comunitárias de saúde, além de funcionárias do poder público também são moradoras da região, isso facilita 0 entrosamento com a comunidade. Durante o tra- balho domiciliar, não seria um bom momento para entender um pouco mais sobreos entravesà participação da comunidade?

Analisando al gumas experiências em participação social dentro do Programa Saúde da Família, Bettiol ${ }^{22}$, notou que diversas abordagens demobilização são utilizadas, porém muitosusuários não querem se comprometer. A autora destacou que há uma certa descrença no processo participativo por parte dos usuários e que além disso, os agentes de saú de têm que concorrer com "a mídia, com as telenovelas e principalmente com o medo de participar da comunidade."

As falas dos entrevistados mostraram que há necessidade de se realizar diagnósticos na área, pois em nenhum momento é perguntado para a população o que eles acham sobre isso e por que não participam.

\section{As percepções dos moradores da região}

Com o intuito de conhecer um pouco mais sobre a realidade em que aquelas comunidades estavam inseridas, no início das entrevistasosmoradores foram questionados sobre os motivos pelos quais moram na região e muitos disseram que foi por necessidade. É pertinente lembrar a rede social em que essas pessoas estão inseridas, pois residem em uma área de proteção ambiental e por conta disso, têm uma série de limitações de ordem geográfica, legal, social e econômica.

Para entender algumas opiniões foram levantadas as representações sociais dos moradores entrevistados quanto ao que é saúde e meio ambiente. Em relação aos resultados obtidos observou-se que mais de $40 \%$ dos moradores entrevistados ainda associam o conceito de saúde à ausência de doença. Apesar de todos os avanços na área da promoção da saúde, essa é uma consequência do próprio processo histórico de evolução do conceito. Em relação à concepção de meio ambiente prevaleceu a representação social de que apenas os elementos da natureza o compõem. É importante ressaltar que apenas uma pequena parcela dos entrevistados incluiu os seres humanos como parte do meio ambiente.

Relacionando os conceitos de saúde e meio ambiente, mais de $85 \%$ dos entrevistados, afirmaram que há uma relação de dependência entre os dois. Em geral, a justificativa esteve relacionada a dois aspectos: a presença da floresta no local, como fator determinante da qualidade do ar, garantindo consequentemente mais saúde para população e a falta de saneamento como fator que prejudica a saúde de todos. 
É interessante notar que em ambas as áreas predominaram as respostas em que as condições ambientais são entendidas como fatores determinantes da saúde, por outro lado, ao conceituarem meio ambiente, foram poucos os que incluíram os seres humanos e ao conceituarem saúde predominou uma visão reducionista do tema.

Quando indagados sobre o trabalho desenvolvido pelas agentes comunitárias de saúde, mais de $77 \%$ dos entrevistados das áreas as conhecem, porém, percebe-se que a comunidade não sabeexatamente definir quais as funções do agente de saúde.

Outro problema inerente a esta questão configura-se pelo trabalho isolado dos agentes de saúde e dos agentes ambientais. Existem diversas relações entre as atividades educativas na área de saúde e ambiental, mas as atividades ainda acontecem de forma fragmentada, o que colabora para que a população não saiba diferenciar os papéis de cada profissional.

Este tipo de prática denota a dificuldade de implementação de ações intersetoriais. Para Junqueira ${ }^{23}$, isso ocorre porque "cada política social encaminha a seu modo uma solução, sem considerar o cidadão na sua totalidade e nem a ação de outras políticas sociais, que também estão buscando a melhoria da qualidade de vida". Se gundo 0 autor a intersetorialidadeengloba a ideia de integração tanto dos problemas sociais quanto de suas soluções.

Fernandez eM ende ${ }^{24}$ corroboram com a afirmação acima ao dizer que assim como a organização do conhecimento e do saber, a administração pública também segue uma lógica compartimentada, dando grande ênfase à responsabilidade por setores.

Considerando as interfaces entre as áreas da saúdee meio ambiente, a intersetorialidadesefaz necessária eurgente, pois a tendência à fragmentação torna-se cada vez mais presente nas práticas de ambas as áreas dificultando a compreensão da problemática e a realização de ações que contribuam com a promoção da saúde.

A percepção dos moradores entrevistados quanto às instâncias de participação

Para discussão e encaminhamento dos problemas locais nas áreas de estudo foram identificadas três instâncias participativas: o Conselho Regional de Saúde, o Conselho de Representantes da região de Paranapiacaba e Parque Andre ense e as Plenárias de Orçamento Participativo que têm como objetivos, respectivamente: deli- berar sobre a Política Municipal de Saúde, estimular o desenvolvimento regional e a ampliação da democracia na gestão da região de Paranapiacaba e Parque Andreense e planejar com a população as prioridades do gasto orçamentário do município por regiões.

Considerando as características da área de estudo, as questões socioambientais e de saúde eram constantes como pautas das reuniões de ambos os conselhos. Durante as entrevistas os moradores foram questionados sobre tais instâncias de partici pação e foi observado que mais de $50 \%$ dos entrevistados no Parque Represa $\mathrm{Bi}$ Ilings III, não conheciam estas instâncias. Entre os que diziam conhecer, dois terços não sabiam explicar para que estes espaços de participação serviam. Já na Chácara Carreiras, a porcentagem de entrevistados que não conheciam essas instâncias participativas ultrapassaram os $60 \%$ e entre os que diziam conhecer, metade não sabia explicar para que serviam.

Quanto à questão da baixa participação em Conselhos ePlenárias, Gohn ${ }^{11}$ afirma que a sociedade civil não tem uma tradição participativa na gestão pública e isso se dá por três motivos: 0 tempo curto deexistência dessas instâncias, a falta de prática em participar desses espaços e a falta de conhecimento de suas possibilidades por parte da população.

Considerando os dados da presente pesquisa, a porcentagem de pessoas que não tinha conhecimento sobre estas instâncias participativas foi significativo, principalmentese considerarmos queem cada tipo deinstância havia representantes da comunidade que passaram por um processo de eleição. Diante do exposto, é preciso re fletir sobre a efetividade desses canais participativos, pois a partir do momento que a constituição de um conselho tem como premissa a inclusão de vários atores e segmentos da sociedade por meio de representação, é essencial que a população conheça estes representantes, principalmente para cobrar o encaminhamento de demandas e ter um retorno quanto aos assuntos tratados nesses espaços.

Weltman ${ }^{25}$ afirma que a questão da representatividadeécomplexa eér realizada deforma simbólica, pois envolve diferentes condições de uso da razão e de juízo, uma vez que o representante tem que deliberar sobre ações que nem ele enem seus representados pensaram, "num sistema re presentativo moderno é a ideia da vontade ou da soberania do povo que são representadas".

Abaixo seguem dois depoimentos distintos sobre cada tipo de Conselho realizado nas áreas 
de estudo que nos remete à relação entre poder público e comunidade sob o ponto de vista dos moradores entrevistados.

Aqui você não pode reformar uma casa, ... e aí eu pergunto pra você onde está a preocupação de um Conselho da Saúde? Como ter saúde se a Prefeitura não dá espaço pra melhorar a nossa casa?. [morador 20]

... o trabalho da Prefeitura, às vezes é até paternalista, criou-se o conselho de representantes, criar não foi uma coisa que se buscou na comunidade, foi estimulada, você colocar condução para as pessoas se deslocarem atéas reuniões, estimular a questão do dia a dia eas pessoas não se apropriarem é uma coisa que até desanima, mas do ponto de vista de participação, tem coisas que eu acho que deveria ser trabal hado meIhor pelo governo, uma coisa queteria que avançar... é discutir ... o que é prioridade para a população... [morador 122]

No primeiro depoimento fica claro que o morador fala da responsabilidade do Conselho de Saúde e da Prefeitura, se abstendo de seu direito de participar e do quanto podetomar parte nas deliberações deste Conselho. 0 segundo morador fala da importância de processos construídos juntos com a comunidade. Segundo ele, ao "oferecer" o canal de participação e uma forma de locomoção, a Prefeitura não possibilita que os moradores se apropriem desta instância, pois não houve diálogo prévio sobre o assunto.

É preciso lembrar que "os mecanismos participativos devem se basear no engajamento popular como um recurso produtivo central" ${ }^{11}$, pois é a população que subsidiará os técnicos sobre os problemas e soluções que necessitam. No mesmo depoimento, o entrevistado classificou a Prefeitura como paternalista por ter estimulado a criação do Consel ho e ainda oferecer transporte para que as pessoas compareçam às reuniões. Paternalismo nada tem a ver com o desenvolvimento das comunidades, mas quando o poder público fomenta espaços de participação como os Conselhos, a participação pode tomar vários sentidos, ou seja, a própria criação do conselho seconstitui como um tipo de participação concedida, cabe ao sujeito transformá-la em uma participação passiva ou ativa.

Bordenave ${ }^{26}$ acredita que a participação concedida pode favorecer o crescimento da consciência crítica e da capacidade de tomar decisões desde que a comunidade saiba aproveitar estes espaços como oportunidades de crescimento e não para o estabelecimento de relações de dependência. 0 que o autor quer dizer é que os membros da comunidade podem simplesmente ignorar que estes espaços existem, apenas marcar presença física ou podem ainda fazer valer suas opiniões nestes espaços, lutando por meIhorias para a comunidade.

A descentralização política ea instauração de Conselhos corroboram com o compartilhamento de decisões entre poder público e sociedade civil, e apesar de todos os desafios engendrados na efetividade deste processo, não podemos negar que a criação dessas instâncias de participação têm grande potencial como alicerce para o desenvolvimento das comunidades.

Além de todas as questões políticas envolvidas é preciso refletir se a população está preparada para a participação, pois como afirma Bordenave ${ }^{26}$, "a participação é uma habilidade que se aprende eaperfeiçoa", portanto, no tocanteà contribuição dos Conselhos para um maior desenvolvimento da comunidade, épertinentelembrar que mais importante que criar a instância participativa é envolver a comunidade nesse processo emuniciá-la por meio da educação para o exercício da participação ativa e deliberativa, daí a importância de se aliar as ações de educação em saúde e ambiental, para que os sujeitos possam exercer essa participação também nos Conselhos locais, de forma crítica e pró-ativa como uma forma de negociação e intervenção na realidade.

Como estimular a participação segundo a percepção dos moradores entrevistados

Como forma de entender a visão dos moradores das áreas de estudo em relação às formas de atuação do poder público local, os entrevistados foram questionados quanto a possíveis ações que os técnicos da Prefeitura poderiam realizar para estimular a população a participar mais das atividades e instâncias participativas da região. As sugestões principais foram: realização de melhorias na região; estudo da realidade do bairro, diálogo com a população e divulgações porta a porta.

Quanto à realização de melhorias no bairro, notou-se a necessidade do morador ter um retorno de suas demandas para que se motive e participe. Os moradores deixaram claro que estar presente nas ações e não ter suas solicitações atendidas desestimula a comunidade e faz com que desacreditem na Prefeitura.

Para Lucas ${ }^{27}$, é importante ter conhecimento do raciocínio existente por trás de al gumas decisões, sobretudo, as políticas, pois do contrário corre-se o risco de haver interpretações errôneas 
fazendo com que enxerguemos determinadas decisões como hostis a nós. Tomar parte em tais ocasiões é imprescindível, pois isso possibilita uma maior compreensão do fato. 0 poder público deve dar retorno à comunidade explicando o que há por trás daquela decisão. I sso pode colaborar inclusive para queo mesmo recuperesua credibilidade etenha um apoio e uma participação maior por parte da comunidade.

A participação deve colaborar para que as pessoas interpretem e critiquem as ações sob o ponto de vista de agentes e não de espectadores. Como já foi citado o ato de participar é um ato educativo, portanto, o diálogo entre poder público e comunidade é essencial. Durante a realização das entrevistas ficou claro que a população sente necessidade de que os técnicos estejam mais próximos da comunidade para que possam ser escutados.

Souza ${ }^{28}$, explica estetipo de "carência" ao afirmar que os interesses e as preocupações das comunidades são elementos-chave no desenvolvimento do processo pedagógico da participação, sendo assi $m$, conhecer a realidade em que os sujeitos estão inseridosé o primeiro passo no estabelecimento de relações com a população.

Ainda como extensão da presença constante do poder público no bairro, percebeu-se que os moradores sentiam falta de maiores explicações quanto às reuniões realizadas. Além disso, muitos disseram que não participam porque nem tomam conhecimento das ações realizadas, por isso indicaram a necessidade de ampliação dos meios de divulgação.

Bordenave $e^{26}$ afirma que "não há participação popular sem informação qualitativamente pertinenteequantitativamenteabundantesobreos problemas, os planos e os recursos públicos". 0 grupo deveconstruir conhecimentos constantementetanto sobre si como sobre seu ambiente e para isso devem existir canais informativos confiáveis.

Um aspecto a se considerar é que o trabal ho de explicar os conteúdos dos follhetos para que tenha real efetividade deve estar atrelado a processos educativos e não se configurar como uma atividade pontual ou de "conscientização", como muitos profissionais dizem. Esse trabalho domiciliar deve ser encarado como um momento de sensibilização dentro de um processo educativo.

É importante lembrar que a conscientização assim como a educação é um processo interno, ninguém écapaz de conscientizar ninguém. Freire citado por Souza ${ }^{28}$, afirma que "a conscientização implica que ultrapassemos a esfera espontânea de apreensão da realidade para chegarmos a uma esfera crítica", cabe ao educador criar condições para que isso ocorra, pois essa criticidade dependede reflexões quesão aprendidas eincorporadas no cotidiano das pessoas por meio da educação.

Segundo Demo5, "a maior virtude da educação... está em ser instrumento de participação política". Todas as sugestões dadas pela comunidade para que o poder público estimule a participação, são condições essenciais dos processos educativos.

Os depoimentos coletados durante as entre vistas mostraram que os funcionários entrevistados tinham consciência das limitações do serviço público, mas de uma maneira geral, avaliando o conjunto de dados desta pesquisa os motivos da falta de participação tanto sob o ponto de vista dos funcionários como dos moradores entrevistados, é em sua grande maioria, externo a eles. Nos depoimentos dos moradores notou-se que a participação é valorizada, mas pareceu queisso era inerente apenas ao discurso, pois muitos nem procuravam saber como poderiam participar das decisões quanto ao que éfeito ou trazido para os bairros, como algo que também traria algum benefício para eles, além de autonomia. Percebe-se uma linha determinista como se as pessoas da comunidade não se reconhecessem como parte desta rede social, daí torna-se evidente que as ações de educação em saúde e ambiental, como processo político se fazem urgentes dentro da perspectiva da promoção da saúde.

Fomentar a participação sob tal perspectiva não é uma tarefa fácil, principalmente quando há tantas dificuldades conjunturais. 0 reforço à ação comunitária pautado na promoção da saúde deve promover a emancipação dos indivíduos, pois como afirma Demo 5 :

"Participação sem autossustentação é farsa... É incorreto definir cidadania como fenômeno meramente político, como se a questão se esgotasse na participação. Faz parte na mesma relevância, a capacidade produtiva. Cidadão pleno participa e trabalha/produz".

São muitos os desafios para concretizar este tipo de participação e o empoderamento da população, mas é por meio da educação crítica e política que esta transformação dos indivíduos se inicia. A partir daí, todos os outros princípios da promoção da saúde também se tornam possíveis, pois o "cidadão pleno que participa e produz", constantemente vai desenvolver suas habilidades pessoais, vai exigir que os profissionais de saúde sejam cada vez mais qualificados e que 
efetivem a criação de políticas públicas eambientes saudáveis.

\section{Consideraçõesfinais}

Diante do exposto evidencia-se que a participação social vista sob o prisma da promoção em saúde deve ser essencialmente política baseada numa relação dialógica entre poder público e sociedadecivil.

No tocante às ações realizadas pelo poder público nas áreas de estudo percebe-sequeainda há muito a se fazer, pois o aprimoramento das práticas educativas já desenvolvidas poderá criar condições para que a população apren da a participar ea lutar pelos projetos demel horia do bai $r$ ro e de sua saúde. Nessa vertente, recomenda-se ao poder público municipal:

. Priorização da intersetorialidade garantindo o diálogo, o planejamento e a realização de ações conjuntas junto às comunidades.

- Realização de um diagnóstico para identificação das reais necessidades da comunidade.

. Fomento e implementação de ações educativas voltadas à participação.
- Implementação de formas de divulgação de informações adequadas à realidade de cada público al vo quese constituam como partedos programas educativos.

. Transparência no trato com a comunidade pautada no diálogo.

Sabe-se que transformar o discurso em práticanem sempreéfácil, porém éautopia deconstruir uma nova realidade sustentável com cidadãos pró-ativos e críticos que deve aprimorar cada vez mais as práticas educativas. Espera-se, portanto, que os dados obtidos por meio desta pesquisa possam colaborar para o desenvolvimento de políticas públicas queestimulem a participação social, a sustentabilidade ambiental ea promoção da saúde eque contribuam principalmente como subsídios aos dirigentes do poder público para que possam refletir sobre suas práticas de modo a tomar decisões junto e em favor do empoderamento da população, da busca de um ambiente mais saudável e de uma significativa melhora na qualidade de vida, sobretudo em áreas com características tão peculiares como as áreas de mananciais.

\section{Colaboradores}

EC Silva contribuiu na execução do trabalho, coleta, análise e interpretação dos resultados, concepção e redação desteartigo. M CF Pelicioni orientou todas as etapas de real ização do trabal ho, bem como sua concepção e delineamento metodológico eparticipou da el aboração, revisão eaprovação final da versão a ser publicada. 


\section{Referências}

1. Freire P. Pedagogia da autonomia: saberes necessários à prática educativa. São Paulo: Paz e Terra; 1996.

2. Brasil. M inistério da Saúde (MS). Promoção da saúde: Carta de Ottawa, Declaração de Adelaide, Declaração de Sundsvall, Declaração de Santafé de Bogotá, Declaração de Jacarta, Rede dos M egapaíses, Declaração do M éxico, Brasília: M S; 2001.

3. Valla VV, Stotz EN. Participação popular, educação e saúde: teoria e prática. Rio de Janeiro: RelumeDumará; 1993.

4. Sawaia BB. Participação social e subjetividade. In: Sposati A; Sawaia BB; Gonçalves CW P, Dallari DA, Tassara E, Scherer-Warren I, Ferreira, LC, Sorrentino, M, Westphal MF, Demo P, Taschner SP. Ambientalismo e participação na contemporaneidade. São Paulo: EDUC, FAPESP; 2001. p. 115-134.

5. Demo P. Participação é conquista: noções de política social participativa. São Paulo: Cortez; 1988.

6. Adorno RCF. A trajetória do movimento e da participação: a conduta dos atores sociais na área de saúde [tese]. São Paulo: Faculdade de Saúde Pública da USP; 1992

7. Bógus CM . Participação popular em saúde: formação política e desenvolvimento. São Paulo: Annablume, FAPESP; 1998.

8. Jacobi PR. Participação. In: Jacobi P, organizador. Encontros e caminhos: formação de educadores ambientais e coletivos educadores. Brasília: Ministério do Meio Ambiente; 2005. p. 231-244.

9. Westphal MF. Participação popular e políticas municipais de saúde: Cotia e Vargem Grande Paulista [tese]. São Paulo: Faculdade de Saúde Pública da USP; 1992.

10. Westphal MF. Promoção da saúde e prevenção de doenças. In: Campos GWS, M inayo MCS, Akerman $M$, Drumond Júnior $M$, CamposYM $C$, organizadores. Tratado de saúde coletiva. São Paulo, Rio de Janeiro: Hucitec, Fiocruz; 2006. p. 635-667.

11. Gohn M G. Conselhos gestores e participação sociopolítica. 3a Edição. São Paulo: Cortez; 2007.

12. Valla VV. Sobre participação popular: uma questão de perspectiva. Cad Saude Publica 1998; 14(Supl. 2):507-518.

13. Organización Panamericana de la Salud (OPAS) Desarrollo y fortalecimiento de los sistemas locales de salud. La participación social en el desarrollo de la salud: experiências latinoamericanas. Washington: OPAS; 1995.

14. Cerqueira MT, Coe GA. Communication, education and participation: a framework and guide to action Washington: Pan American Health Organizaton 1996. (HPP/HPL/96.3).

15. Gadotti M, Gutiérrez F. Educação comunitária e economia popular. 4a Edição. São Paulo: Cortez; 2005. (Questões de nossa época, n. 25).
16. Organización Panamericana de la Salud (OPAS) Desarrollo y fortalecimiento de los sistemas locales de salud en la transformacion de los sistemas nacionales de salud: la participación social en el desarrollo de la salud. Washington: OPAS; 1994.

17. Pelicioni M CF. Educação em saúde e educação ambiental: estratégias de construção da escola promotora da saúde [tese]. São Paulo: Faculdade de Saúde Pública; 2000.

18. Instituto Brasileiro de Geografia e Estatística (IBGE). São Paulo: IBGE; 2000. [acessado 2007 out. 21]. Disponível em: http://www.ibge.gov.br

19. Brasil. Ministério da Saúde. Conselho Nacional de Saúde. Resolução no. 196 de 10 de outubro de 1996. Diretrizes e Normas Regulamentadoras de Pesquisas Envolvendo Seres Humanos. Diário Oficial da União 1996; out 16

20. Brasil. M inistério da Saúde (MS). Conselho Nacional de Saúde. Resolução 304 de 9 de agosto de 2000. Diário Oficial da U nião 2000; ago 10

21. Bardin L. Análise de conteúdo. Lisboa: Edições 70; 2006.

22. Bettiol LM. Saúde e participação popular em questão: o Programa Saúde da Família. São Paulo: Editora UNESP; 2006.

23. Junqueira LAP. Intersetorialidade, transetorialidade e redes sociais na saúde. Rev Adm Pública 2000; 34(6):35-45.

24. Fernandes JCA, M endes R. Gestão local e políticas públicas para a qualidade de vida. In: Fernandes JCA, M endes $R$, organizadores. Promoção da saúde e gestão local. São Paulo: Aderaldo \& Rothschild, Cepedoc: 2007.

25. Weltman FL. Democracia, representação, participação: a aposta do pluralismo institucional. Divulg saúde debate 2008; (43):29-36

26. Bordenave JED. 0 que é participação. 8a Edição. São Paulo: Brasiliense; 2007. (Coleção Primeiros Passos).

27. Lucas R. Democracia e participação: pensamento político. Brasília: Editora Universidade de Brasília; 1985.

28. Souza ML. Desenvolvimento de comunidade e participação. 5a Edição. São Paulo: Cortez; 2008.

Artigo apresentado em 21/05/2011

Aprovado em 13/08/2011

Versão final aprovada em 14/09/2011 